\title{
Dieulafoy lesion in the colon: a rare cause of lower gastrointestinal bleeding
}

Dieulafoy lesion is an uncommon cause of gastrointestinal bleeding [1, 2]. It is most often located in the proximal portions of the gastrointestinal tract, but unusual locations such as the colon have also been reported. It is defined by a large and tortuous submucosal arteriole that protrudes through the mucosal layer and may be a cause of massive and recurrent bleeding $[3,4]$. The clinical presentation is variable and consists of hematemesis, melena, hematochezia, enterorrhagia, or anemia of unknown cause [4]. Common endoscopic findings are the presence of a superficial protruding vessel in a small mucosal defect (with or without active bleeding) and the presence of fresh clot adherent to a tiny defect in the normal gastrointestinal mucosa $[3,4]$.

Endoscopic treatment is the method of choice, and success rates are above $90 \%$. Surgery may be required for severe and refractory bleeding and after failure of endoscopic therapy (which occurs in $5 \%$ of cases) [2-4].

A 79-year-old woman diagnosed with bone metastatic breast cancer was admitted with complaints of asthenia, lack of appetite, and intermittent lower gastrointestinal bleeding. At admission, her hemoglobin level was $7.3 \mathrm{~g} / \mathrm{dL}$. After initial resuscitative measures, upper digestive endoscopy was performed and revealed no significant findings. During colonoscopy, active bleeding from a small vessel (Dieulafoy lesion) in the ascending colon was observed ( $\mathbf{F i g} \mathbf{1}$ ). Endoscopic therapy with three throughthe-scope hemoclips was successfully carried out ( $\triangleright$ Video 1 ). An endoscopic tattoo with nanquim ink was performed at the bleeding site in case of recurrence or a need for surgical intervention ( $>$ Fig. 2). The patient was discharged after 6 days with normal hemoglobin levels and no signs of rebleeding.

Endoscopy_UCTN_Code_CCL_1AD_2AF

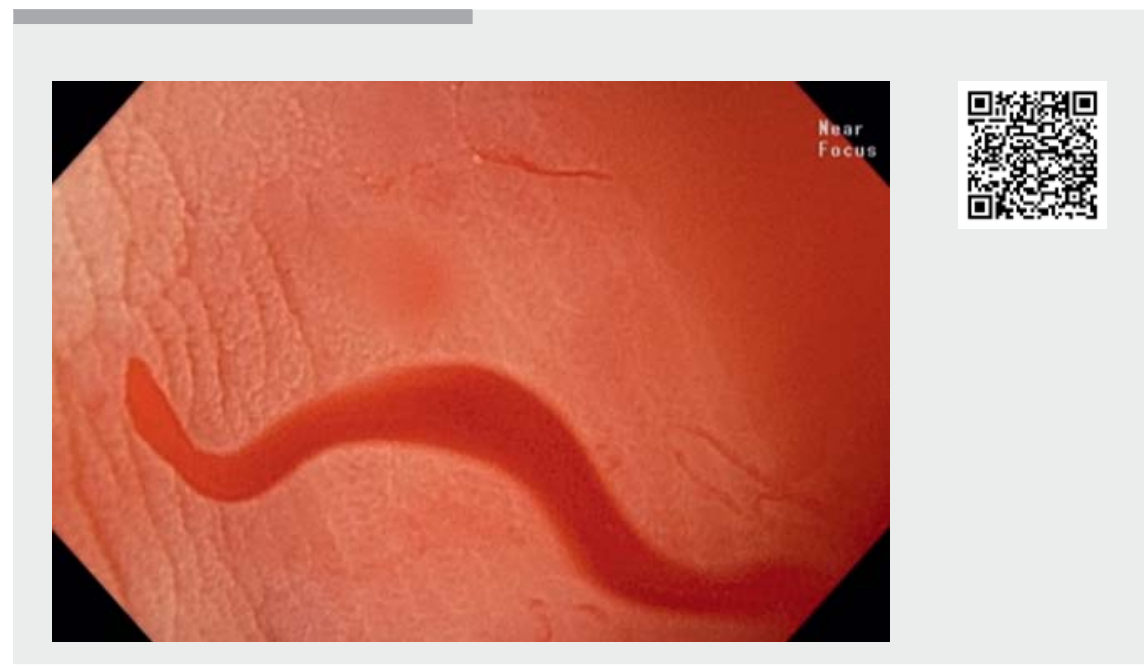

$\checkmark$ Video 1 Endoscopic diagnosis and treatment of a Dieulafoy lesion in the colon.

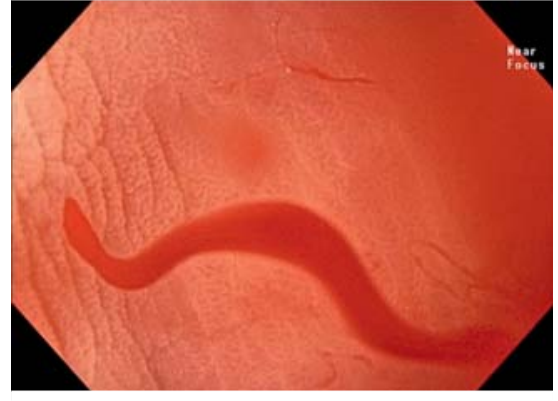

- Fig. 1 Active bleeding from a Dieulafoy lesion in the colon of a 79-year-old woman: underwater view.

\section{Competing interests}

The authors declare that they have no conflict of interest.

The authors

José L. Paccos, Natália S. Mukai, Paulo A. F. P. Correa, Fernando P. Marson, Fernando L. Mota, Fernando J. Savóia de Oliveira, Eduardo M. A. Pereira Junior Department of Digestive Endoscopy, Hospital Sírio-Libanês, São Paulo, Brazil

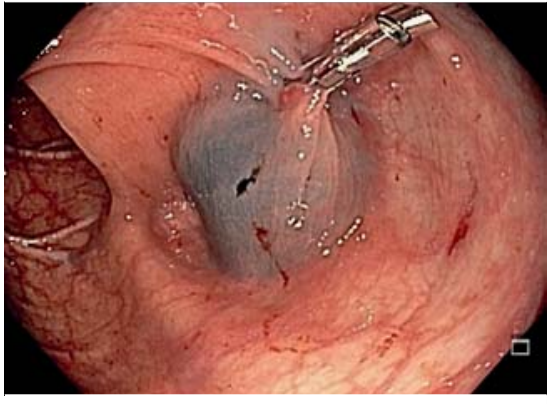

- Fig. 2 Final endoscopic appearance after endoscopic tattooing.

\section{Corresponding author}

Fernando P. Marson, MD

Department of Digestive Endoscopy, Hospital Sírio-Libanês, Rua Dona Adma Jafet, 91, São Paulo, Brazil marsonfp@gmail.com 


\section{References}

[1] Christopher MC, Hundal R, Cheng EJ. Colonic Dieulafoy's lesion: a rare cause of lower gastrointestinal hemorrhage and review of endoscopic management. Case Reports in Gastrointestinal Medicine 2014; 1: 1-5

[2] Baxter M, Aly EH. Dieulafoy's lesion: current trends in diagnosis and management. Ann R Coll Surg Engl 2010; 92: 548-554

[3] Fukita Y. Treatment of a colonic Dieulafoy lesion with endoscopic hemoclipping. BM] Case Rep 2013; 1: 1-2

[4] García AZG, Blanco AP, Pérez DN et al. Management of colonic Dieulafoy lesions with endoscopic mechanical techniques: report of two cases. Dis Colon Rectum 2004; 47: 1539-1543

Bibliography

Endoscopy 2021; 53: E313-E314

DOI 10.1055/a-1270-6655

ISSN 0013-726X

published online 8.10 .2020

(c) 2020. Thieme. All rights reserved.

Georg Thieme Verlag KG, Rüdigerstraße 14,

70469 Stuttgart, Germany
ENDOSCOPY E-VIDEOS

https:/|eref.thieme.de/e-videos

回局 Endoscopy E-Videos is a free access online section, reporting 靣: on interesting cases and new techniques in gastroenterological endoscopy. All papers include a high quality video and all contributions are freely accessible online.

This section has its own submission website at

https://mc.manuscriptcentral.com/e-videos 